\title{
Getting to COP27: Bridging Generational Divide
}

\author{
Anna Stanczyk ${ }^{1}$ \\ Published online: 3 March 2022 \\ (c) Society for International Development 2022
}

\begin{abstract}
United Nations Secretary General António Guterres, in his address to the UN General Assembly called the world leaders to bridge the divide among generations. There is no current issue that divides the generations more, than the urgency of climate action and accelerating clean energy transition. With the COP26 in Glasgow behind us, and less than 10 months until COP27 in Sharm-el Sheikh what can and should be done to encourage this inter-generational dialogue? How can young people and the civil society exercise their power to push the climate justice agenda forward?
\end{abstract}

Keywords COP27 · COP26 - Energy transition $\cdot$ Youth $\cdot$ Climate change $\cdot$ Civil engagment

\section{Generational Divide}

On 21 September 2021, the United Nations Secretary-General António Guterres addressed the General Debate on the 76th Session of the United Nations General Assembly. In his opening remarks, he called on world leaders to bridge the divide among generations. He continued that the past generations failed to respond adequatly to many of the global challenges we are facing today. Young women and men, however, are taking the steering wheel in an effort to make a real change in the fight for human rights and dignity for all, gender equality and climate action. Guterres underlined the need to harness young people's talent, energy, and ideas and expand opportunities for today's and future generations. Support is not enough; they need a seat at the table. ${ }^{1}$ The SG could sense a growing gap in how we see the world and how we want to work for our shared future.

This divide appears even more expansive in the context of the climate crisis and clean energy transition. Young women and men are demanding actions to secure their future. They are well aware of the "code red for humanity', ${ }^{2}$ and that immediate action needs to be taken to avert a catastrophe. Naturally, there is much more at stake for them than for those over 50. Their seriousness stands in stark contrast with the

Anna Stanczyk

A.STANCZYK@unido.org

1 United Nations Industrial Development Organization, Vienna, Austria 'dangerous lack of urgency' 3 displayed by those representing them.

At the same time, industrialization and trade lifted millions of people out of poverty while leaving many behind, especially women and young people. It also resulted in significant environmental degradation ${ }^{4}$ and put the Earth on the course to climate catastrophe. The appetite for energy is growing, and rightfully so. Energy is a prerequisite for education, development, quality health services, and economic growth. Renewables cannot meet the global electricity demand based on the current trends and policies. ${ }^{5}$ Coalfired electricity is set to reach an all-time high this year. ${ }^{6}$

COP26 in Glasgow came at a pivotal time in history. The implication of the climate crisis and reliable energy flows and the ongoing COVID-19 pandemic alongside the rise of nationalism, and soaring geopolitical tensions, tangibly impact security, contribute to rising energy prices, and increases the pressure on young women and men. With 8 years to go to achieve Sustainable Development Goals

\footnotetext{
${ }^{1} \mathrm{https}: / / \mathrm{www}$. youtube.com/watch?v=x9kce_ciwNI.

${ }^{2}$ https://www.un.org/sg/en/content/secretary-generals-statement-theipcc-working-group-1-report-the-physical-science-basis-of-the-sixthassessment.

${ }^{3}$ https://www.youtube.com/watch?v=9xUgoxagJJA.

${ }^{4}$ https://www.unido.org/sites/default/files/files/2017-11/DG_Broch ure_February_2015_Web_0_0.pdf.

5 https://www.iea.org/news/global-electricity-demand-is-growingfaster-than-renewables-driving-strong-increase-in-generation-fromfossil-fuels.

${ }^{6}$ IEA, Electricity Market Report https://iea.blob.core.windows.net/ assets/01e1e998-8611-45d7-acab-5564bc22575a/ElectricityMark etReportJuly2021.pdf, accessed 7 January 2022.
} 
(SDGs), it looks like collectively and individually, we are falling short.

\section{Falling Short}

COP26 negotiations were a balancing act between the needs of the developing and the financial capacity of developed countries. The developing world aims to meet the rising demand for reliable and modern energy, which is crucial for economic growth. At the same, time putting the world on a pathway to net-zero and adapting to the devastating consequences of climate crisis. This is why, the Glasgow Climate Pact references sustainable development multiple times. ${ }^{7}$ Simultaneously, developing countries struggle to acknowledge their responsibility for the 'loss and damage' related to harm caused by man-made climate change. ${ }^{8}$ The pledge of $\$ 100$ billion a year of climate finance remains unfulfilled. Concrete and reliable financing for adaptation, which is a matter of survival to the Small Island Developing States (SIDS), will be again the on the table in Sharm el-Sheikh. All these questions are related to the concept of climate justice, from the crossroads of ethics, law and politics. COP27 will be the place to watch for the answers.

Despite rather chilly coverage in the media, COP26 was a success in many ways. It was the first time that coal was mentioned in COP documents. Although the final language stalled, at the already infamous, 'phasing down' coal instead of the initial 'phasing out', it was a turning point when the international community recognized the time for fossil fuels as a source of energy is up. Furthermore, Nigeria, India, Vietnam, Thailand, and Nepal made net-zero commitments. In total, $90 \%$ of the world's economy is currently committed to net-zero.

The Global Energy Alliance for People and Planet (GEAPP) launched marked a turning point for philanthropic capital that overlooks clean energy projects. Under its umbrella, the US-led initiative, Power Africa, brought together more than 160 private sector partners onboard to accelerate clean energy access for sub-Saharan Africa. Moreover, in a surprising announcement, USA and China pledged to boost their climate cooperation over the next decade, committing towards a transition to clean energy and decarbonization in their joint declaration. Finally, and in order to put pressure and move faster, the Glasgow Climate Pact asked countries to propose emissions-cutting targets by next year (2022) at COP27, rather than in the traditional 5 year bracket.

\footnotetext{
7 Glasgow Climate Pact, https://unfccc.int/sites/default/files/resource/ cop26_auv_2f_cover_decision.pdf, accessed 7 January 2022.

8 https://news.un.org/en/story/2021/11/1105222.
}

However, the Glasgow Climate Pact still falls short in many aspects, and it was unable to meet its aspirations and objectives. It was unsuccessful in setting a concrete pathway to deliver the promise of a clean energy transition by 2030 and achieving SDG 7, which calls for 'ensuring access to affordable, reliable, sustainable and modern energy for all'. Although it acknowledges the need for financial flows to the countries that need to adapt to climate change, it fails to mention any concrete commitments. The reality is that if the 2030 goals are to be met, investments in renewable energy and energy efficiency need to be tripled. Mobilizing adequate and predictable finance, shifting subsidies from fossil fuels to renewables, and putting a price on carbon are all crucial in accelerating the energy transition and will need to be addressed at the next COP. A number of concrete steps, including funds mobilization, addressinbg the digital divide, harnessing innovation, technology, and data collection and application are still to be taken. The skills necessary to push energy transition forward are still not readily available for young women and men in the developing world. This gap is contributing to a mismatch in the job market and lost potential for economic growth. ${ }^{9}$

\section{Youth and Civil Society in the Spotlight}

It was COP26 that showcased the power of youth to demand the future they deserve. Almost 400 young people from 186 countries worked on the 'Youth4Climate Manifesto' delivered to the COP26 Presidency. It was a vital point; these young women and men working together across national interests. My personal experience working with this constituency underlines this point. I had the privilege to work alongside young women and men, mostly volunteers whilst organizing the Youth for Vienna Energy Forum (VEF). It was the first time for the VEF and for UNIDO to host an event designed by and for youth, in which the civil society could express their needs and directly engage with high-level speakers. The level of interaction, passion, and knowledge at this event suggested that young people are hungry for concrete actions and a meaningful seat at the table. I also had a feeling that these young people are committed to fighting for climate justice. It was therefore not a surprise that this time around, youth and public empowerment got their own 'day' (5th November) at COP26.

Young men and women are, as a matter of fact, already on the frontlines of energy transition and the for fight climate justice. It is up to international organizations, governments, and the private sector to realize this and provide them with the support and spotlight they deserve. The shift from

\footnotetext{
9 https://www.un.org/sites/un2.un.org/files/2021-twg_1-091021.pdf.
} 
looking at youth as beneficiaries to youth as innovators and creators is yet to happen in many places, both in the public and private spheres. There are some compelling examples, however, emerging. The Youth Sustainable Energy Hub is one of these. A team of enthusiastic volunteers showcases how young women and men are at the forefront of working toward the achievement of SDG7 in their communities through implementing renewable energy projects. They organize capacity-building workshops and collect lessons learned to inspire youth worldwide. I met Norah Magero, a bright-eyed Kenyan, during her online interview to become a Youth Champion for the Youth for VEF. She was in the field, working on the initiative she co-founded-Drop Access. This non-profit has redefined off-grid energy access in rural areas, provides financing and trains rural communities in renewable energy technologies. It champions energy for productive uses and cold storage solutions. The latter being a response to the COVID-19 pandemic.

\section{Leave No One Behind}

On energy day (4 November) at COP26, sustainability and inclusiveness of the clean energy transition were being debated when the ideas just transition and climate justice were introduced. The prices of uptake of renewables continue to fall, and getting to net-zero is no longer a technological challenge..$^{10}$ The clean energy transition poses political and sociological challenges. Although it has clear environmental, health, and economic benefits and is essential to keep global warming below $1.5^{\circ} \mathrm{C}$, it requires a shift from the status quo. In the short term, it will affect communities that depend on fossil fuels as a source of income. It will disproportionally affect those in the developing countries, where the financial resources for reskilling (and shifting to newer, less polluting technologies) are scarce. This is why redirecting public financing away from fossil fuels, and equitable sharing of the rewards from the transition is crucial. Although inevitable, this change is often unpopular and difficult politically, often dependent on political cycles and the prevailing poiltical sentiments at home. Nevertheless, the concerns of the affected communities, such as loss of only income, are valid. At the same time, we need to ask if this transition engages sufficiently women, youth, and indigenous communities and whether it mobilizes all the available talents.

$\overline{10}$ https://www.iisd.org/articles/just-transition-examples.

\section{Lagging Behind}

COP26 was a crucial stepping stone and should be treated as such. I tend to make a point of dismissing the cynics, including some well-recognized climate activists, that brush off the complexities and implications of the transformation of the whole energy sector. According to the Intergovernmental Panel on Climate Change (IPCC), energy is the key to tackling climate crisis. ${ }^{11}$ UNFCCC Executive Secretary Patricia Espinosa concurs, 'energy is at the heart of the climate change emergency and it must be at the heart of its solution. A swift and broad transition to renewable energy will be essential to achieve the emission reduction goals laid down by the Paris Agreement'. Two-thirds of global greenhouse gas emissions can be attributed to $\mathrm{CO}_{2}$ from fossil fuel combustion and industrial processes. ${ }^{12}$

Accelerating the transition to low-carbon, climate-neutral, reliable and sustainable energy systems offers additional socio-economic and security benefits such as job creation, improvement in air quality, social inclusion and energy security.

\section{Energy Efficiency}

In order to achieve clean energy transition and therefore the SDG7, we need to look into what is lagging. SDG target 7.3 calls for doubling the improvement in energy efficiency. ${ }^{13}$

The progress remains insufficient and uneven despite the obvious benefits. Energy-efficient buildings and appliances offer great opportunities to reduce energy intensity by $40 \%$ of residential and up to $50 \%$ of commercial buildings. ${ }^{14}$ Furthermore, energy efficient products support economic development, energy security, achieve climate targets and promote the economic empowerment of women and youth. ${ }^{15}$ Among the bariers to introduce relevant policies, there is a lack of awareness among the policymakers and the public alongside the data about the possible savings. There is limited capacity, when it comes to the policy design, but most importantly market monitoring and technical implementation. In a short run, inefficient products are cheaper for the consumer, hence affordability remains a key barrier in the developing communities. The answers are already there: digitalization

\footnotetext{
11 https://www.ipcc.ch/2020/07/31/energy-climatechallenge/.

$12 \mathrm{https} / / /$ unfccc.int/news/the-world-needs-a-swift-transition-to-susta inable-energy.

13 https://sdg-tracker.org/energy.

14 https://iea.blob.core.windows.net/assets/d9090f84-fd5a-464b976a-99c7905c9c57/PerspectivesfortheEnergyTransition-TheRoleofE nergyEfficiency.pdf.

15 https://www.viennaenergyforum.org/wp-content/uploads/2021/10/ VEF-Policy-Brief-Products.pdf.
} 
technology can close the digital and data divide, while international institutions should provide institutional, policy and technical capacities. Looking at energy-as-service and other innovative financing solutions can reduce the cost of entry of energy efficient products. ${ }^{16}$

\section{Industry}

Although industry accounts for $24 \%$ of global greenhouse gas emissions, relatively flat emissions are the trend in the past years. ${ }^{17}$ Heavy industries such as cement, steel, aluminium and chemical, in particular rely on fossil fuel, as alternatives are not yet economically viable to produce hightemperature heat. In this regard, the improvement of energy efficiency, electrifications of end-users using renewables, focusing on direct renewable heat and biomass, indirect use of renewable electricity thought feedsocks, e-fuels and green hydrogen are all pieces of the bigger puzzle. The application of carbon capture and storage technologies as a transitional solution for economies heavily dependent on fossil fuels can be applied in some cases. ${ }^{18},{ }^{19}$ The action plan includes the alignment of energy and industrial policies to ensure that no one is left behind by having skills and tools necessary to contribute to the transition. Limited skills and knowledge remain key bottlenecks. Increased investments in research and development as well as innovation would allow Small and Medium Entrepreses (SMEs) and hard-to abate sectors to transition to renewables. Stimulating the demand for lowcarbon products and services is both in the hands of public and private sector. Yet again, digitalization is imperative to better data and transparency, which leads to better decision making by both the government and the industry.

\section{Food Systems}

Despite increased productivity, current food systems fail to provide adequate food supply and contriubute to one third of global greenhouse gas emissions and environmental degradation. The COVID-19 pandemic highlighted the vulnerability of exisiting systems, especially in the countries relying heavily on agricultural imports or foreign workers. ${ }^{20}$ Food production is particularly vulnerable to the impacts of climate change. The leave no one behind principle in the food

\footnotetext{
16 https://www.viennaenergyforum.org/wp-content/uploads/2021/10/ VEF-Policy-Brief-Products.pdf.

17 https://www.iea.org/reports/tracking-industry-2020.

18 https://www.irena.org/-/media/Files/IRENA/Agency/Publication/ 2020/Sep/IRENA_Reaching_zero_2020.pdf.

19 https://www.irena.org/publications/2021/Jun/World-Energy-Trans itions-Outlook.

20 https://www.viennaenergyforum.org/wp-content/uploads/2021/10/ VEF-Policy-Brief-Food-Systems.pdf.
}

systems transformation has crucial implications for youth, women and communities in remote areas in terms of job creation, reduction of workload and positive health implications. Therefore, digital tools and reliable data have the power to derisk investmens, improve access to finance and foster innovation and entrepreneurship. A holistic approach to policy environment and its effective coordination between government institutions, both national and local can unlock the benefits of integration of sustainable energy in food systems. Last, but not least, looking into new financing models, clustering smaller investments and demand stimulation have the potential to improve the investment environment in developing countries. ${ }^{21}$

\section{No Time for Cynicism. It is Time to Lead}

In his COP26 speech, former US President Barack Obama referred to 'cynicism as the recourse of cowards'. He underlined the need for empathy and perseverance as vital components in addressing the complicated issues involved and suggested that everything was not as clear-cut as some might suggest. He suggested that the young renewable energy leaders, fighters, and doers need to dispense with cynicism; and rather transform their anger and respond to adversities with kindness, innovative approaches, and enthusiasm.

This kind of leadership and eagerness to get everybody on board in climate diplomacy is lacking. The US's 4-year absence from the climate negotiations stage left a void yet to be filled. There is plenty that the world leaders and policymakers, and international organizations should learn from young men and women advocating for climate action not only because they are accountable to them as voters and future torchbearers. However, they should always aim for an honest conversation rather than tokenism and display similar character and courage needed in the climate negotiations.

There is no single voice of youth, nor should there be. Working with young leaders has exposed a few challenges that are yet to be tackled. Youth councils are instrumental and effective in building long-term relationships and providing quality inputs. However, they have a limited reach and tend to omit vulnerable populations. They also require a significant commitment from the organization regarding time and resources that are scarce. ${ }^{22}$

However, young men and women are crucial to accelerating energy transition as advocates, policymakers, innovators, researchers, skilled workers and entrepreneurs. Similarly to all of the previous revolutions aligned with the discovery of

\footnotetext{
${ }^{21}$ https://www.viennaenergyforum.org/wp-content/uploads/2021/10/ VEF-Policy-Brief-Food-Systems.pdf.

22 https://www.oecd.org/mena/governance/Young-people-in-OG.pdf.
} 
new energy sources, installation of energy infrastructure and development of new end-use technologies were the factors that drove industrialization, employment, innovation and empowerment. In my discussions and consultations with youth representatives, always two pillars come up as necessary to support their full and meaningful involvement. First of all, there is a need to enhance access to quality futureproof skills. Skills for the job market of tomorrow are still not being tought sufficiently at educational institutions, creating education-employment gap and closing many job opportunities for young graduates, especially from developing world. Furthermore, very often entrepreneurial attidutes are not nurtured sufficiently during education and training programmes. ${ }^{23}$ Secondly, the environment is not enabling young innovators and entrepreneurs with optimal regulation, access to finance and technology exchange to foster young women and men to take calculated risks of starting their own business and exploring their idea, that leads to innovation and job creation.

These two pillars are crucial to support young women and men to lead and reap the benefits of the transformation of the energy sector across all three earlier mentioned themes of energy efficiency, industry and food systems.

\section{Getting to COP27 in Sharm-el-Sheikh}

Egypt is set to host the subsequent COP negotiations on behalf of the African continent. It allows the developing world, already at the front line of climate change, to set the agenda. It will focus, most likely, on climate adaptation financing, establishing a monitoring framework for emission reduction targets. Water scarcity and quality were announced as leading themes of the conference. In terms of energy transition, the area of food systems, might be of special focus due to its strategic importance for the African continent.

This time around, avenues for youth and civil society to be engaged in the COP27 side events and negotiations remain to be communicated. The next two COPs are taking place in the Midde East and North Africa (MENA) region. It allows and obliges MENA youth to take the center stage. Children and young people (0-24 year old) currently account for nearly half of the region's population and hold significant potential to bring about change. The MENA region, however suffers from world's lowest level of youth civic engagement. ${ }^{24}$ Taking the lead in clean energy transition and achieveing the Paris Agreement offers multiple

\footnotetext{
23 https://sdgs.un.org/sites/default/files/2020-07/Youth_Entreprene urship.pdf.

24 https://reliefweb.int/report/egypt/mena-generation-2030-investingchildren-and-youth-today-secure-prosperous-region.
}

opportunities for young men, and women in particular, to reach their full potential by reaping the beneftis of aquiring new future-proof skills and taking advantage of the enabling environment of the just transition that aims to leave no one behind. New jobs created by renewables are an answer for the highest in the world youth unemployment. It only shows that young women and men in MENA region have a great deal to gain and therefore an incentive to get involved.

One way to get your hands dirty and get involved is to reach out to youth constituencies of the international organizations, governments or non-governmental youth organizations.

Youth constituencies offer great opportunities for this and for meeting like-minded and enthusiastic young people who are ready to share their already impressive experience in policy advocacy and capacity building. Those interested in achievement of SDG7, should definitely get in touch with United Nations Major Group for Children and Youth and SDG7 Youth Constituency. ${ }^{25}$ Another option is Children and Youth constituency to UNFCCC, UN Agency leading COP negotiations. ${ }^{26}$

Student Energy is a global and youth-led organization that empowers young people to accelerate clean energy transition $^{27}$ through advocacy work, building capacity and resource mobilization. BRICS Youth Energy Agency (YAE) promotes collaboration in the energy sector among Brazil, Russia, India, China and South Africa. It focuses on strengthening the cooperation between BRICS countries in the fields of research, awareness raising and promoting youth-led projects. It also engages with government institutions and experts. ${ }^{28}$

There are a few aspects to watch out for on the path to the COP27 and monitor closely if the pulse of the $1.5^{\circ} \mathrm{C}$ target is not weakening further. First of all, what are the follow-up actions in the context of the rules on reporting emissions and international carbon trading?

Secondly, how much more ambitous are the Nationally Determinded Contributions in comparison those presented a year earlier? The next thing to watch is how the developed world meets its financial pledge of $\$ 100$ billion, ${ }^{29}$ especially with respect to the promised adaptation funds crucial for the developing world in facing the climate crisis.

For the next 10 months, youth and civil societies have an opportunity to pressure their national governments and regional organizations to step up and raise their

\footnotetext{
25 https://www.unmgcy.org/sustainable-energy.

${ }^{26} \mathrm{http}: / / \mathrm{www}$.youngo.uno/.

${ }^{27} \mathrm{https}: / /$ studentenergy.org/about/.

${ }^{28}$ https://yeabrics.org/.

${ }^{29} \mathrm{https} / / /$ unfccc.int/news/un-climate-chief-urges-countries-to-deliv er-on-usd-100-billion-pledge.
} 
emissions-cutting ambitions for COP27. This is particularly important in the countries that emit the most. Those biggest emitters have the chance to lead by example and move from targets to laws and policies on their respective national stages, such as the Build Back Better Act in the USA and Green Deal in the European Union.

It is also instrumental in engaging and pressuring local and municipal governments and cities to make pledges and turn the commitments into actions on the local level. COVID-19 recovery offers an opportunity to build back better and shift investments to more sustainable solutions. Youth and civil society enthusiasm should translate into political and civil engagement by running for office and taking your time to vote.

You have a chance to be the force of change in your community, school, university and company by organizing local climate summits and talking with somebody that disagrees with you. Listening with empathy, going outside your bubble challenges and refines your ideas. Intergenerational dialogue is the only way to bridge that great divide, it will allow us to learn from the past, while fighting to the transformational change that is necessary.

Change is painful and complicated and it is in human nature to resist. As with every transition, justice might not be the guiding principle of it, but the bottom line for youth is that this time around no one is left behind.

Publisher's Note Springer Nature remains neutral with regard to jurisdictional claims in published maps and institutional affiliations. 